\title{
Spatial variation of altitudinal belts as dividing index between warm temperate and subtropical zones in the Qinling-Daba Mountains
}

\author{
ZHAO Fang ${ }^{12}$, LIU Junjie ${ }^{1}$, ZHU Wenbo ${ }^{1},{ }^{*}$ ZHANG Baiping ${ }^{3}$, ZHU Lianqi ${ }^{1}$ \\ 1. College of Environment and Planning, Henan University, Kaifeng 475004, Henan, China; \\ 2. Key Laboratory of Geospatial Technology for the Middle and Lower Yellow River Regions, Henan University, \\ Kaifeng 475004, Henan, China; \\ 3. State Key Laboratory of Resource and Environment Information System, Institute of Geographic Sciences \\ and Natural Resources Research, CAS, Beijing 100101, China
}

\begin{abstract}
To determine the dividing index between warm temperate and subtropical zones based on the spectra of altitudinal belts, this paper collected 33 spectra of altitudinal belts in the Qinling-Daba Mountains from published literatures and then analyzed the structures and the spatial patterns from south to north, from west to east and based on exposure directions. The results show that: 1) From south to north, the basal belt gradually changes from subtropical evergreen broadleaf forest to warm temperate deciduous broadleaf forest; the spectra of altitudinal belts change from complex to simple; the dominant belt changes from montane broadleaf-conifer mixed forest and evergreen-deciduous broadleaf mixed forest to deciduous broadleaf forest. 2) From west to east, the structures of the altitudinal belt spectra show complexity in the east and west but simplicity in the middle section; the upper limits of both the evergreen-deciduous broadleaf mixed forest belt and montane deciduous broadleaf forest belt present a quadratic curve distribution pattern in the longitudinal direction. However, the upper limit of the montane broadleaf-conifer mixed forest belt exhibits a nearly linear decrease in the west-east direction. 3) Both the north and south slopes in the Qinling Mountains have the similar basal belt, whereas it varies greatly between the north and south slopes in the Daba Mountains. Comparably, dominant belts are very similar in the Qinling Mountains and the north slope of the Daba Mountains, but the south slope of the Daba Mountains has its own unique dominant belt: evergreen-deciduous broadleaf mixed forest. This implies that the Daba Mountains are more appropriate than the Qinling Mountains to act as the boundary between subtropical and warm-temperate zones in central China.
\end{abstract}

Keywords: Qinling-Daba Mountains; mountain altitudinal belt; latitude; longitude; quadratic curve

Received: 2020-01-06 Accepted: 2020-02-10

Foundation: National Natural Science Foundation of China, No.41601091; Scientific Research Start-up Funding of the Program Supporting Special Talent Zone (Henan University); Integrated Scientific Investigation of the North-South Transitional Zone of China, No.2017FY100900

Author: Zhao Fang, PhD and Lecturer, specialized in mountain physical geography and mountain ecological environment. E-mail: zhaofang84@163.com

"Corresponding author: Zhang Baiping, Professor, specialized in physical geography and applied GIS. E-mail: zhangbp@1reis.ac.cn 


\section{Introduction}

The Qinling-Daba Mountains, within the watersheds of both the Yangtze River and Yellow River, form a natural boundary of geography and climate between north and south China, which are primarily important to the formation and variation of the geographic and ecological environment in central China. They extend from the Qinghai-Tibet Plateau in the west to the eastern plain of China, across 8 degrees of longitude in the east-west direction, forming a "bridge" that connects the Qinghai-Tibet Plateau and the eastern plain of China. Therefore, their physical geography is characterized by connection in the east-west direction and transition in the north-south direction, and zonation and azonation factors work together to form complex and diverse mountain altitudinal belts. Research on the structure, characteristics, quantity, height, and distribution mode of the altitudinal zonation structure plays a crucial role in exploring the complex ecological and geographic patterns in the Qinling-Daba Mountains, recognizing the specific location of the north-south divide of China, and explaining the mountain biodiversity and its response to global climate changes.

The zonal vegetation has obvious variation from south to north in the Qinling-Daba Mountains, mainly exhibited in vegetation composition with a gradual transition from evergreen broadleaf forest to deciduous broadleaf forest gradually (Lei, 1999; Wu and Hou, 1980). Therefore, the Qinling-Daba Mountains are considered to represent the climate boundary of subtropical and warm temperate zones, that is, the boundary of south and north. However, the specific location of the boundary has been controversial for decades. Three locations have been proposed over the years: the main ridge of the Qinling Mountains (Zhu, 1958; Wu and Hou, 1980; Hou, 1981), the south slope of the Qinling Mountains (Zhang and Zhang, 1979; Zhang, 1981; Kang and Zhu, 2007) and the north slope of the Qinling Mountains (Huang, 1959; Guang et al., 1961; Hou, 1988). An important reason for this uncertainty is that the boundary is a transitional ecotone rather than a sharp line, and the geographical zonation is complex and diverse; this phenomenon is called multi-dimensional zonality. It is related to factors such as the horizontal zonality difference between the north and the south, vertical differentiation of vegetation due to temperature variation with altitude (Hou, 1964), landscape zonal differences on different flanks (Liu and Lu, 1990), substances on the ground surface, and mass elevation effect. These aspects of multi-dimensional zonality (including latitudinal zonality and azonality) are generally overlapping and thus can be difficult to distinguish. Evergreen broadleaf forest, for example, appears both on the south slope and at lower latitudes than the deciduous broadleaf forest on the northern slope in the Qinling Mountains (Lei, 1999). Can such variation be attributed to latitudinal zonality or exposure effects? To investigate this multi-dimensional zonality and determine the exact boundary of the south and north, mountain altitudinal belts in the Qinling-Daba Mountains, as the primary reflection of the mountain environment (Zhang et al., 2006), need to be recorded and analyzed from different dimensions: north-south, west-east, and different flanks.

As a complete north-south transitional zone, the Qinling-Daba Mountains span six provinces including Shaanxi, Gansu, Sichuan, Chongqing, Hubei and Henan. Extending from Diebu of Gansu eastwards to Shennongjia of Hubei, with a total east-west length of over $1000 \mathrm{~km}$ and an area of about 300,000 $\mathrm{km}^{2}$, they include the Qinling Mountains in Shaanxi, the Funiu Mountains, the West Qinling Mountains of southern Gansu, northwest Sichuan 
and the Daba Mountains. The vegetation, soil and climate of these mountains have been surveyed and analyzed by scholars previously. Field surveys of soil and vegetation distribution have been conducted by Ying (1994), Zhu and Yue (2001), Yue et al. (2000) and Fu et al. $(1996,2004)$ in the Qinling Mountains. Tang and Fang researched the temperature pattern of Taibai Mountain (Tang and Fang, 2006), the main peak of the Qinling Mountains. Gao (1986), Shen et al. (2004) and Xue and Wang (2010) also surveyed the plant characteristics and vegetation types in Shennongjia, Micang Mountain in the Daba Mountains. Li and Zhang researched the plant flora of Lianhuashan in the west of the Qinling-Daba Mountains (Li and Zhang, 2000). However, few comprehensive surveys and analyses on the altitudinal distribution of vegetation belts in the Qinling-Daba Mountains have been conducted. Studies on the Qinling-Daba Mountains are typically narrowly focused on the central Qinling-Daba Mountains rather than the whole area (Liu, 1995). Consequently, geographic data from different mountains are found in different publications, and therefore tend to be fragmental and local. Determining how to integrate these fragmental and local vegetation data scientifically to model mountain altitudinal belts in the Qinling-Daba Mountains has become an urgent issue.

With the development of modern earth observation technology, geographic information system (GIS) technology and network technology, mountain altitudinal belts GIS have been developed, making digitalization and integration of the altitudinal belts in the Qinling-Daba Mountains possible (Zhang et al., 2006). Moreover, theories of mountain altitudinal zonation and quantification of mass elevation effect provide theoretical support for revealing of the multi-dimensional zonation of the mountain altitudinal belts in the Qinling-Daba Mountains (Han et al., 2011; Zhao et al., 2014; Zhao et al., 2015). For this paper, 33 spectra of altitudinal belts in the Qinling-Daba Mountains were collected from the literature, and these belts were standardized and digitalized based on a classification system and a geographic information system for mountain altitudinal belts (Zhang et al., 2006). The altitudinal distribution patterns were then systematically analyzed from three dimensions including "from south to north", "from east to west" and "north-south slope comparison" to reveal the multi-dimensional zonality of the Qinling-Daba Mountains and explore the location of the boundary between warm temperate zone and northern subtropical zone.

\section{Data and method}

A dataset of 33 spectra of altitudinal belts in the Qinling-Daba Mountains was collected from publications such as Vegetation of Shaanxi (Lei, 1999) as well as research papers by Gao (1986), Ying (1994), Fu et al. (1996), Yue et al. (2000), Zhu and Yue (2001), Fu (2004), Shen et al. (2004), and Xue and Wang (2010). Our research area includes: the Lianhua Mountain of Gansu, the shady slope of Hutou Mountain in the western Qinling Mountains, Taibai Mountain, Foping Nature Reserve, Yingzuishi, Niubeiliang, Caolianling and other area in the central Qinling Mountains, the Funiu Mountains in the eastern Qinling Mountains, Micang Mountain in the central Daba Mountains, Shennongjia Nature Reserve in the east, Baishuijiang Nature Reserve, Dabanzhao, and Xuebaoding in the west. The locations of the altitudinal belts are shown in Figure 1. 


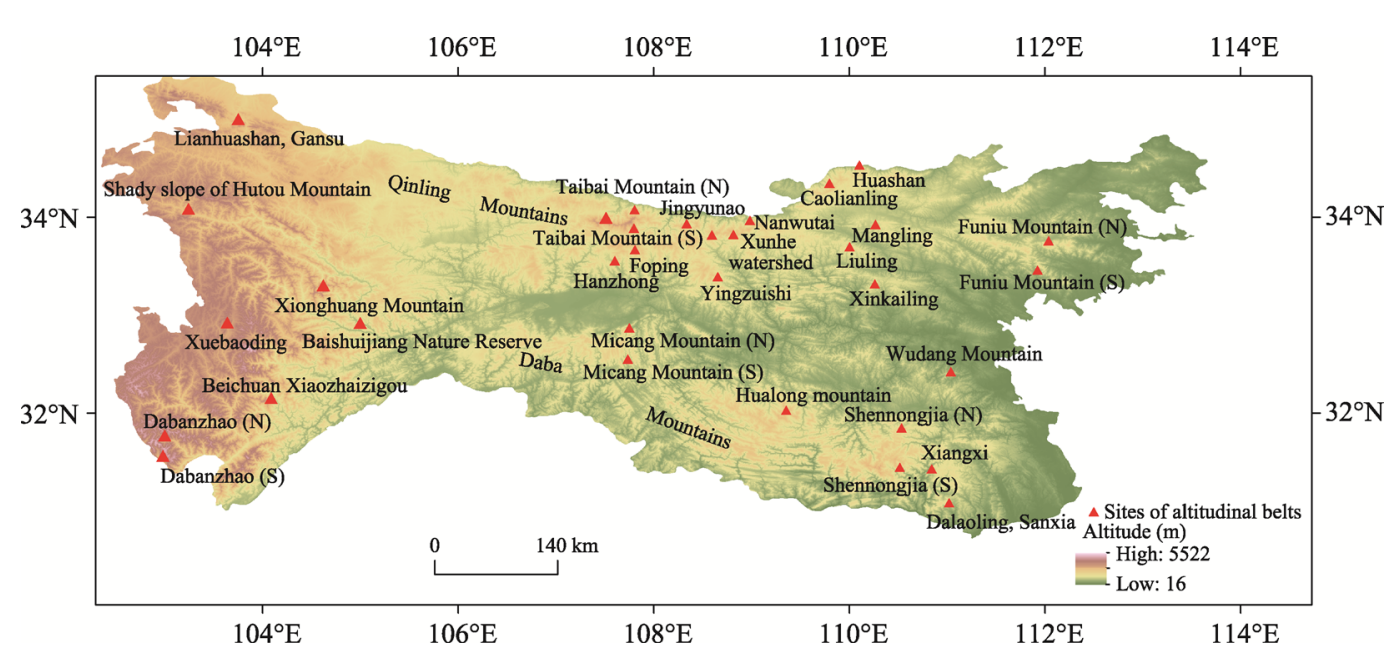

Figure 1 Data sites of altitudinal belts in the Qinling-Daba Mountains

Based on a classification system, the altitudinal belts recorded in the Qinling-Daba Mountains were standardized and integrated to a uniform geographic information system. Data integration followed several principles: 1) The base belts are consistent with the vegetation type in the horizontal zones. Referring to Vegetation of Shaanxi (Lei, 1999) and Vegetation of China (Wu and Hou, 1980), this paper takes protogenic cork oak and holm oak forests as the base belt of the north slope of the Qinling Mountains, and deciduous broadleaf forests containing evergreen trees as the base belt of the south slope of the Qinling Mountains. 2) With the altitudinal belt standardization system (Zhang et al., 2006) as a reference, the nominating methods for the base belts and mountain altitudinal belts are different. The former is named as biological "climate zone + vegetation type", whereas the latter is named as "landform + vegetation type". For example, the base belt of the north slope of Taibai Mountain is called a warm temperate deciduous broadleaf forest belt, while the mountain altitudinal belts above the base belt are called as montane deciduous broadleaf forest belt. 3) If there are several descriptions for the boundary of the same altitudinal belts, the classification method in the more authoritative literature sources will be adopted. For example, according to Vegetation of Shaanxi and Vegetation of China, 1980), the deciduous broadleaf forest belt is distributed at 1200-2100 $\mathrm{m}$ in Yingzuishi, Caolianling, and Niubeiliang in the central Qinling Mountains, whereas it is termed broadleaf-conifer mixed forest belts by Liu and $\mathrm{Lu}$ (1990). Hence, the former classification is adopted in this paper. 4) In the case of slope direction differences in the altitudinal belts, records are made separately according to different aspects. 5) If the boundary of a mountain altitudinal belt is a transitional ecotone rather than a sharp line, the middle position of this transition ecotone is recorded as the location of the boundary. For example, as described by Shen et al. (2004), the upper limit of the evergreen-deciduous broadleaf mixed forest on the south slope of Shennongjia is at $1700 \mathrm{~m}$, whereas the lower limit of deciduous broadleaf forest is at $1600 \mathrm{~m}$. At the regional scale, the mean value of $1650 \mathrm{~m}$ is taken as the elevation of the boundary.

On this basis, according to three dimensions, including "from south to north", "from east to west" and "north-south slope comparison": 1) the structure, characteristics, 
quantity, height, and width-dominant belt of altitudinal belts in the Qinling-Daba Mountains are systematically analyzed; 2) the spatial distribution patterns of the altitudinal belts are determined, so that transition, diversity, complexity and multi-dimensional zonality of vegetation distribution in the Qinling-Daba Mountains, as the north-south transitional zone, are revealed; 3) new evidence for the distribution of the north-south divide of China is provided.

\section{Results}

\subsection{Latitudinal variation of altitudinal belts in the Qinling-Daba Mountains}

As shown in Figure 2, the basal altitudinal belts from south to north in the Qinling-Daba Mountains change gradually from a subtropical evergreen broadleaf forest belt (on the south slope of the Daba Mountains) to a subtropical evergreen-deciduous broadleaf mixed forest belt (on the north slope of the Daba Mountains) and a warm temperate deciduous broadleaf forest zone (on the north slope of the Qinling Mountains). The distribution ranges, respectively, are 400-1300 m (Lei, 1999; Shen et al., 2004) on the south slope of the Daba Mountains, 200-1800 m (Ying, 1979; Gao, 1986; Lei, 1999) on the north slope of the Daba Mountains, 200-1300 m (Lei, 1999; Ye et al., 1999; Yue et al., 2000) on the south slope of the Qinling Mountains and 300-1300 m (Lei, 1999; Ye et al., 1999; Shen et al., 2001) on the north slope of the Qinling Mountains. For mountains with similar elevation, the structure of the altitudinal belts changes from complex to simple. For example, subtropical mountain areas under 2000 m (e.g., Dalaoling in Sanxia, Xiangxi, and the south slope of Shennongjia) generally comprise three sub-zones: subtropical evergreen broadleaf forest, montane evergreen-deciduous broadleaf mixed forest, and montane deciduous broadleaf forest (or montane broadleaf-conifer mixed forest belt). In addition to a few mountains in the Funiu Mountains, the Qinling Mountains mainly comprise two sub-zones, namely, warm temperate deciduous broadleaf forest and montane deciduous broadleaf forest, but lack the

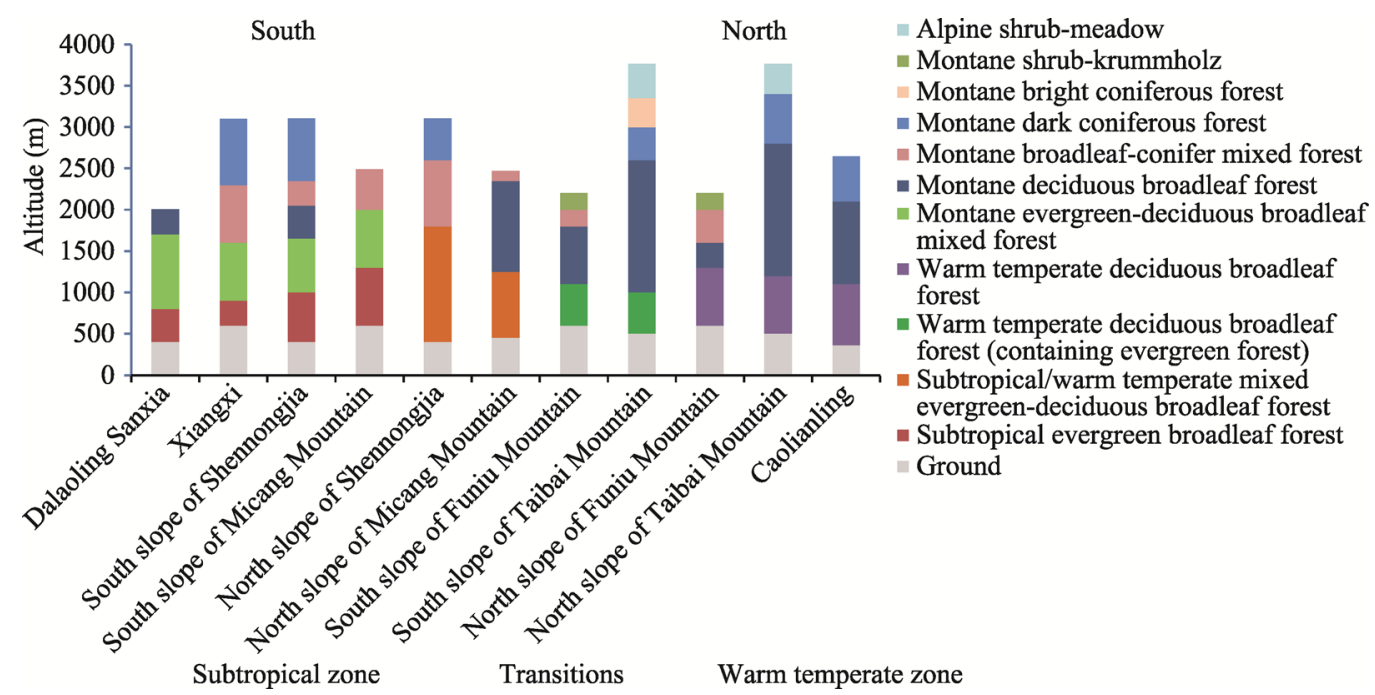

Figure 2 North-south variation of altitudinal belt spectra in the Qinling-Daba Mountains 
subtropical evergreen broadleaf forest belt. The dominant belts change from montane evergreen-deciduous broadleaf mixed forest and montane dark coniferous forest to montane broadleaf-conifer mixed forest and montane deciduous broadleaf forest. As shown in Figures 3-5, the upper limits of the evergreen-deciduous broadleaf mixed forest belt, montane deciduous broadleaf forest belt, and montane broadleaf-conifer mixed forest belt do not correlate obviously with latitude from south to north.

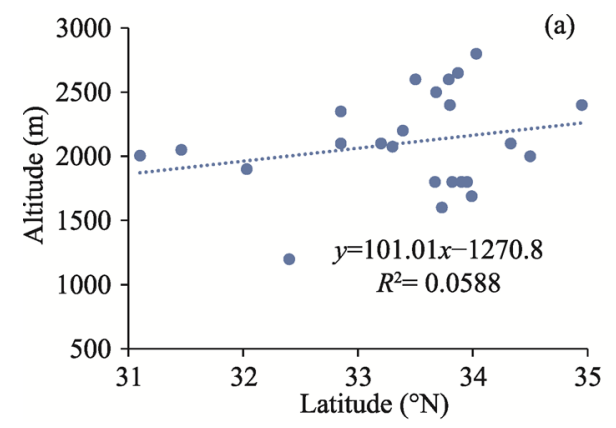

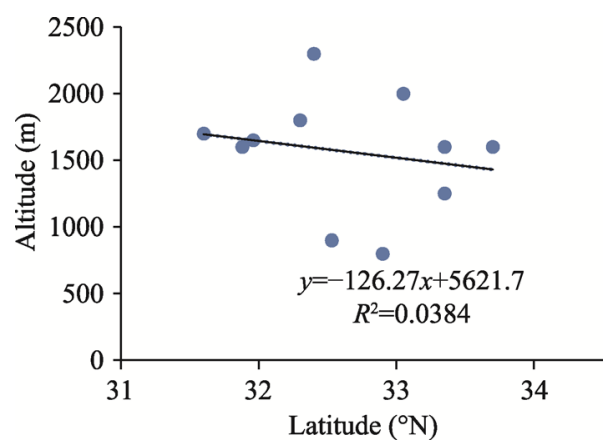

Figure 3 Latitudinal distribution of the upper limit of the evergreen-deciduous broadleaf mixed forest belt in the Qinling-Daba Mountains

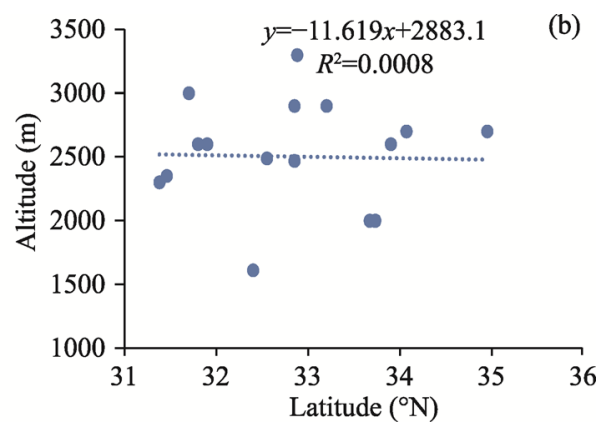

Figure 4 Latitudinal distribution of the upper limits of the montane deciduous broadleaf forest belt (a) and broadleaf-conifer mixed forest belt (b) in the Qinling-Daba Mountains

\subsection{Longitudinal variation of altitudinal belts in the Qinling-Daba Mountains}

The structure of altitudinal belts in both the Qinling and Daba mountains is characterized by "complex-simple-complex" (Figures 5-7). Specifically, the quantity of altitudinal belts in the central-east Qinling Mountains decreases from 4 in the Funiu Mountains to 3 westward, involving Caolianling, Mangling, Liuling, the Xunhe Basin and Yingzuishi at first, and then increases to 4-5 for Taibai Mountain and the Xushui Basin. The dominant belts are montane deciduous broadleaf forest, except for montane broadleaf-conifer mixed forest on the north slope of the Funiu Mountains. For the central-east of the Daba Mountains, the number of belts decreases from 3-5 sub-belts in the east of Shennongjia to 3 sub-belts from Micang Mountain westward. The dominant belts on the south slope are different from those on the north slope. On the north slope, there is a change from mountain broadleaf-conifer mixed forest and montane dark coniferous forest to montane deciduous broadleaf forest westward. On the south slope, evergreen-deciduous broadleaf mixed forest and montane dark coniferous forest turn into montane evergreen-deciduous broadleaf mixed forest.

The structures are complex and generally comprise 4-6 sub-belts in the western Qinling-Daba Mountains (Figures 5-7). Specifically, Lianhuashan Nature Reserve, Gansu in the western Qinling Mountains has a mountain steppe belt particular to the semi-arid region, whereas the shady slope river valley zone of Hutou Mountain has a dry and hot 
valley shrub belt. Baishuijiang Nature Reserve in the western Daba Mountains has the most complex altitudinal belt structure with as many as six belts, and the dominant belt is montane broadleaf-conifer mixed forest. The dominant belts in Beichuan Xiaozhaizigou Nature Reserve and Xuebaoding are the subalpine bush woody meadow, nival and subnival belts.

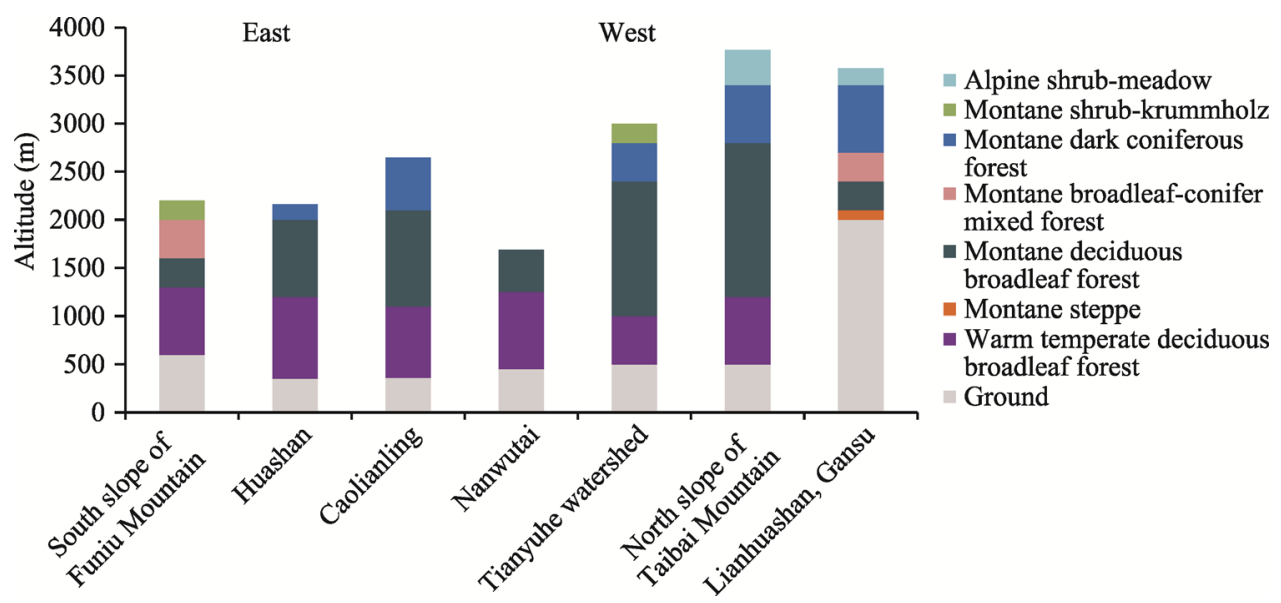

Figure 5 Mountain altitudinal belts from east to west on the north slope of the Qinling Mountains

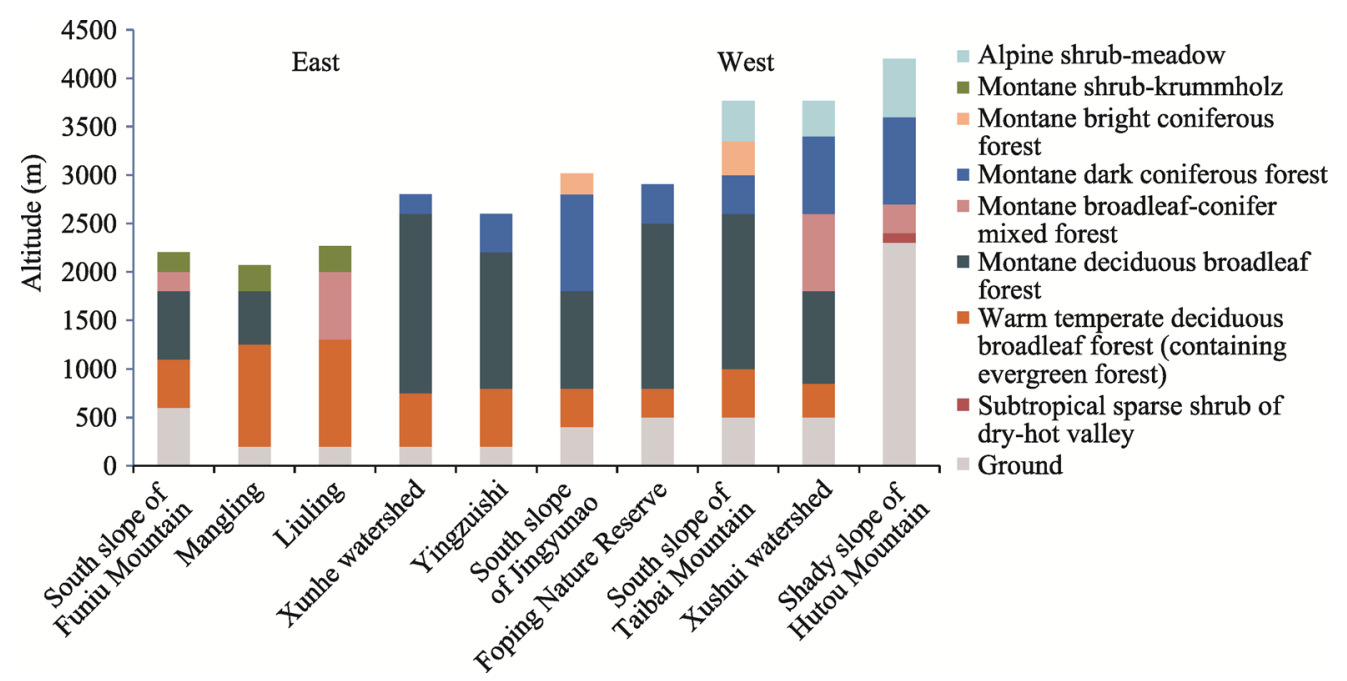

Figure 6 Mountain altitudinal belts from east to west on the south slope of the Qinling Mountains

The relationship between the upper limit of the evergreen-deciduous broadleaf mixed forest and longitude can be described by a convex quadratic curve in the Qinling-Daba Mountains (Figure 8). The lowest value of the upper limit of the evergreen-deciduous broadleaf mixed forest belt is located at $111^{\circ} \mathrm{E}$ in the Wudang Mountain, and the distribution altitude is as low as $800 \mathrm{~m}$ (Rao, 1993). The highest point is located in the Beichuan Zhaizigou Nature Reserve at $104^{\circ} \mathrm{E}$, with a distribution altitude of $2300 \mathrm{~m}$ (Huang, 1988). 


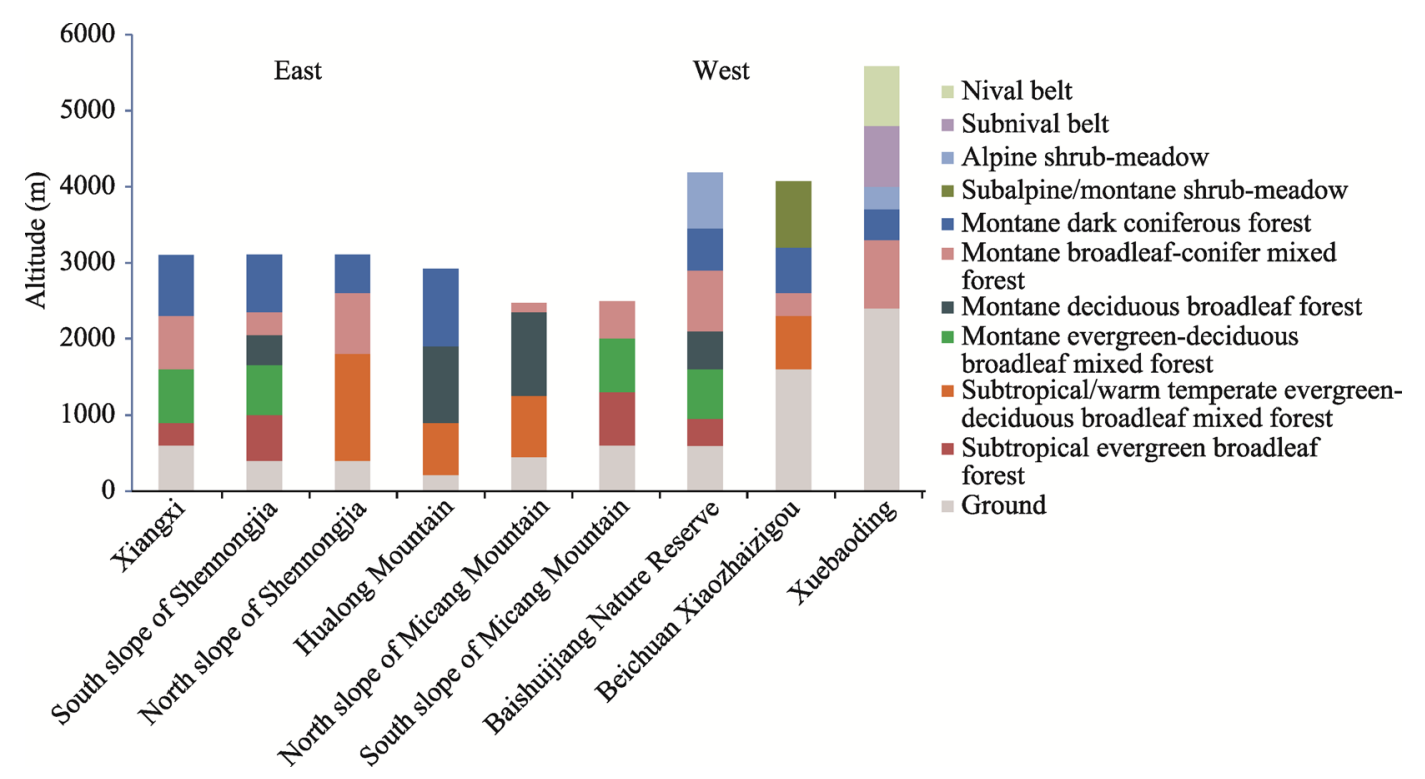

Figure 7 Mountain altitudinal belts from east to west in the Daba Mountains

The relationship between the upper limits of montane deciduous broadleaf forest and longitude can also be fitted by a convex quadratic curve in the Qinling-Daba Mountains (Figure 9). The highest locations of the montane deciduous broadleaf forest belt are both at $108^{\circ} \mathrm{E}$. The peak of the central Qinling Mountains is at Taibai Mountain with the upper limit reaching $2800 \mathrm{~m}$ (Lei, 1999), whereas it appears on the north slope of Micang Mountain in the Daba Mountains, with the upper limit reaching $2350 \mathrm{~m}$ (Lei, 1999). The lowest distribution of the upper limit of montane deciduous broadleaf forest in the Qinling Mountains is located at $112^{\circ} \mathrm{E}$ in the Funiu Mountains, with an upper limit of only 1600-1800 $\mathrm{m}$ (Ye et al., 1999), whereas in the Daba Mountains, it occurs at $111^{\circ} \mathrm{E}$ in Wudang Mountain, with an upper limit of only $1200 \mathrm{~m}$

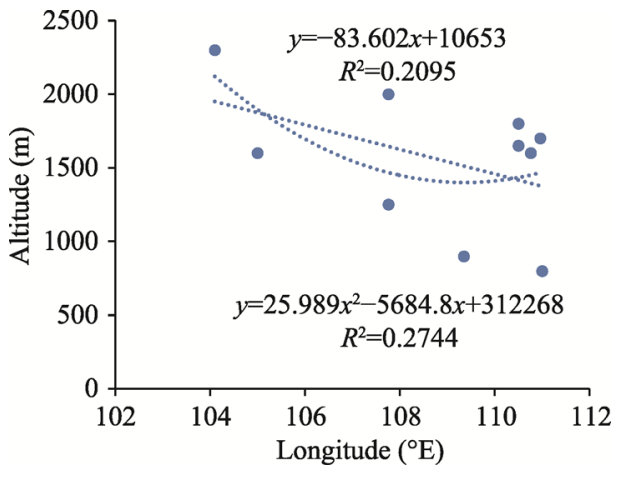

Figure 8 Longitudinal distribution of the upper limit of the evergreen-deciduous broadleaf mixed forest belt in the Qinling-Daba Mountains (Rao, 1993).
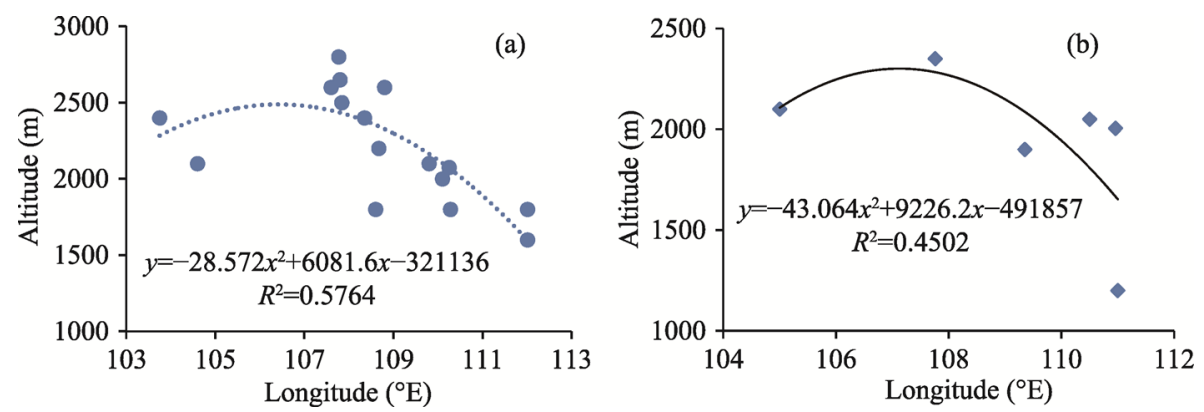

Figure 9 Longitudinal distribution of the upper limit of the montane deciduous broadleaf forest belt in the Qinling (a) and Daba (b) Mountains 
From west to east, the upper limits of montane broadleaf-conifer mixed forest show an obvious linear trend with longitude (Figure 10). Their highest locations are at Lianhuashan Nature Reserve in southern Gansu and Diebu Forest Zone, in western Qinling Mountains, with the upper limit reaching $2700 \mathrm{~m}$ (Feng and Zhang, 1990; Li and Zhang, 2000). The upper limit decreases eastward to $2600 \mathrm{~m}$ (Lei, 1999) in the Xushui Basin of central Qinling Mountains and decreases to $2000 \mathrm{~m}$ (Ye et al., 1999) in the Funiu Mountains. The highest distribution in the Daba Mountains is located at Xuebaoding in the western region, with the upper limit reaching $3300 \mathrm{~m}$ (Luo, 1983; Yao et al., 2010). It decreases eastwards to $2900 \mathrm{~m}$ (Sun and Feng, 1998) in Baishuijiang Nature Reserve in southern Gansu, keeps decreasing eastward to $2480 \mathrm{~m}$ (Lei, 1999) on the south slope of Micang Mountain and decreases to $2300 \mathrm{~m}$ (Gao, 1986) on the south slope of Shennongjia. The lowest location is on Wudang Mountain; limited by mountain height, and the upper limit is only $1600 \mathrm{~m}$ (Rao, 1993).
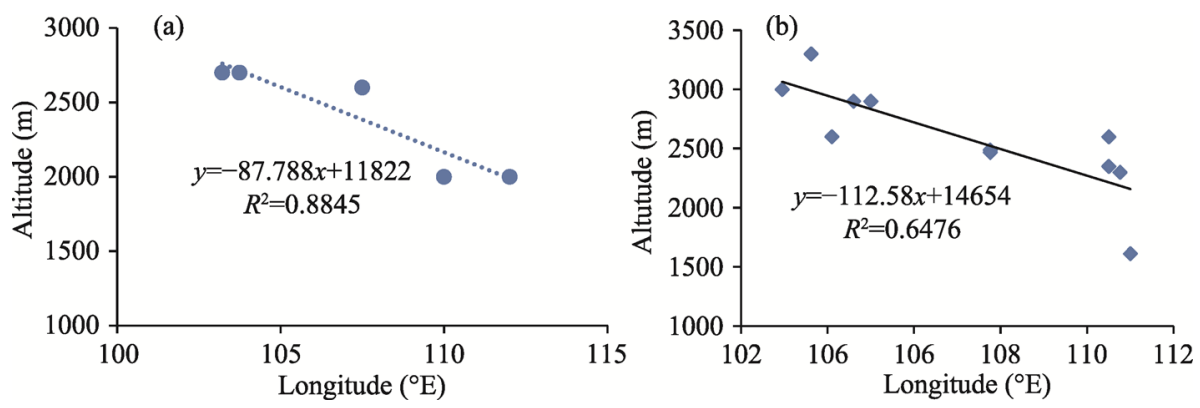

Figure 10 Longitudinal distribution of the upper limit of the broadleaf-conifer mixed forest belt in the Qinling (a) and Daba (b) Mountains

\subsection{Exposure effect of altitudinal belts in the Qinling-Daba Mountains}

The Qinling and Daba mountains are mountain ranges with an east-west trend in central China, and the mountain altitudinal belts have obvious differences between the south and north slopes. The base belts of the north and south slopes in the Qinling Mountains are warm temperate deciduous broadleaf forest, but there are evergreen tree species on the south slope. The structures of the mountain altitudinal belt on both south and north slopes of the Funiu Mountains in eastern Qinling are completely the same that both include montane deciduous broadleaf forest, montane broadleaf-conifer mixed forest, and peak bush krummholz. However, the altitudinal belts are obviously different in terms of height and width, as shown in Figure 2. The upper limit of the montane deciduous broadleaf forest belt on the south slope of the Funiu Mountains reaches 1800 m, 200 m higher than on the north slope. However, its lower limit on the south slope is $200 \mathrm{~m}$ lower than that on the north slope. Thus, this belt is $400 \mathrm{~m}$ wider on the south slope than on the north slope, with the breadth reaching up to 700 $\mathrm{m}$. Thus, it becomes the dominant belt of the south slope. Comparatively, the dominant belt on the north slope is the montane broadleaf-conifer mixed forest belt. For Taibai Mountain in the central Qinling Mountains the dominant belts on both slopes are montane deciduous broadleaf forest. However, there is a montane bright coniferous forest sub-belt (larch subzone) on the south slope, which is not found on the north slope. Therefore, there is one more mountain altitudinal belt on the south slope than on the north slope, with five altitudinal belts on the south slope, and four on the north slope. In addition, according to Vegetation of 
Shaanxi (Lei, 1999), the upper limit of the montane deciduous broadleaf forest belt on the south slope of Taibai Mountain is $200 \mathrm{~m}$ lower than that on the north slope, whereas the upper limit of the montane dark coniferous forest belt is $400 \mathrm{~m}$ lower on the south slope than on the north slope.

The base belt on the north slope of the Daba Mountains is evergreen-deciduous broadleaf mixed forest, whereas it is evergreen broadleaf forest on the south slope. There are 4-5 sub-belts on the south slope of Shennongjia in the eastern Daba Mountains, and the dominant belts are montane mixed evergreen-deciduous broadleaf forest and montane dark coniferous forest (Shen et al., 2004). There are only 3 subzones on the north slope which lacks a montane evergreen-deciduous broadleaf mixed forest zone. The dominant belts are montane broadleaf-conifer mixed forest and montane dark coniferous forest (Gao, 1986; Ying, 1979). There are three altitudinal belts on both south and north slopes of Micang Mountain, but the dominant belts on the south slope are the montane evergreen-deciduous broadleaf mixed forest belt, and that on the north slope is montane broadleaf deciduous forest.

\section{Conclusions and discussion}

The results show that the base belts of mountain altitudinal belts gradually change from subtropical evergreen broadleaf forest to warm temperate deciduous broadleaf forest with an increase of latitude from south to north in the Qinling-Daba Mountains. The spectra of altitudinal belts change from complex to simple. The dominant belts shifted from evergreen-deciduous broadleaf mixed forest to montane deciduous broadleaf forest and mountain broadleaf-conifer forest. The results imply that the latitudinal zonality of the Qinling-Daba Mountains is mainly controlled by the north-south temperature gradient. However, the upper limits of the evergreen-deciduous broadleaf forest belt, montane deciduous broadleaf forest belt, and montane broadleaf-conifer mixed forest belt do not have obvious correlation with latitude. This phenomenon is related to the mountain mass structure - the main ridge line of the Qinling Mountains is inclined toward the north, and the base elevation increases northward from the Hanjiang valley in the south piedmont of the Qinling Mountains to the ridge line. The mass elevation effect is gradually enhanced, such that the limits of the mountain altitudinal belts tend to increase to a certain extent. Thus, the south-to-north decrease of the altitudinal belts is compensated for the increase of mass elevation and the latitudinal zonality is destroyed. For the same reason, the upper limit of the montane deciduous broadleaf forest belt on Taibai Mountain, which has north-inclined latitude and high terrain, reaches 2600-2800 m (Lei, 1999), and the upper limit is 100-300 m (Yue et al., 2000) higher than the vegetation limit in Foping Nature Reserve on the south side. In the Baishuijiang Nature Reserve with north-inclined latitude and high terrain, the distribution of the broadleaf-conifer mixed forest belt is $600 \mathrm{~m}$ (Sun and Feng, 1998) higher than that in Shennongjia Natural Reserve with slightly lower latitude and terrain. It is necessary to research how the mass elevation effect influences the distribution of altitudinal belts further in the Qinling-Daba Mountains.

From east to west, with the variety of longitude, the mountain altitudinal belt structures in the Qinling and Daba Mountains manifest complex-simple-complex characteristics. The dominant belt in the central eastern part of the Qinling Mountains is montane broad- 
leaf-conifer mixed forest or montane deciduous broadleaf forest, which translate westwards to montane dark coniferous forest in southern Gansu. The dominant belts on the north slope of the Daba Mountains change from montane broadleaf-conifer mixed forest and montane dark coniferous forest to montane deciduous broadleaf forest. On the south slope, they change from montane evergreen-deciduous broadleaf mixed forest and montane dark coniferous forest to montane evergreen-deciduous broadleaf mixed forest and finally to subalpine bush meadow in northwest Sichuan. These results reflect that the longitudinal zonality of the Qinling-Daba Mountains is controlled by the east-west moisture gradient. However, the high terrain in the west and low terrain in the east lead to complicated changes of the mountain altitudinal belts. From west to east, the moutane evergreen-deciduous broadleaf mixed forest and montane deciduous broadleaf forest in the Qinling-Daba Mountains show a quadratic curve in the longitudinal direction, which is consistent with the quadratic curve hypothesis of mountain altitudinal belt distribution in China (Zhang et al., 2006). The upper limits of the montane broadleaf-conifer mixed forest belt show a significant linear decrease trend in the longitudinal direction.

The results of this paper also indicate that it is more appropriate to take the Daba Mountain as the north-south divide in comparison with the Qinling Mountains. At first, the horizontal zones on the south and north slopes of the Qinling Mountains are similar, as both mainly comprise warm temperate deciduous broadleaf forest-deciduous oak forests (Lei, 1999). Evergreen shrubs and small arbors appear in the base belts of south slope of the Qinling Mountains, but these evergreen plants do not become dominant (Lei, 1999). In contrast, zonal vegetation on the south and north slopes of the Daba Mountains changes obviously. The base belt on the south slope of the Daba Mountain is subtropical evergreen broadleaf forest (Lei, 1999; Shen et al., 2004), whereas the base zone on the north slope is warm temperate (subtropical) evergreen-deciduous broadleaf mixed forest, suggesting that the Daba Mountains have stronger zonal variation effects on vegetation in comparison with the Qinling Mountains.

Second, the structures and types of mountain altitudinal belts on the south and north slopes of the Qinling Mountains are quite similar. For example, the south and north slopes of the Funiu Mountains in the eastern Qinling Mountains have montane deciduous broadleaf forest, montane broadleaf-conifer mixed forest, and mountain bush krummholz, and both south and north slopes of Taibai Mountain in the central Qinling Mountains have montane deciduous broadleaf forest, montane coniferous forest, and alpine bush meadow (Lei, 1999). There are obvious differences between the south and north slopes of the Daba Mountains. There are montane evergreen-deciduous broadleaf mixed forest and broadleaf-conifer mixed forest on the south slope of the Daba Mountains, whereas there are montane deciduous broadleaf forest and montane broadleaf-conifer mixed forest on the north slope (Lei, 1999). In addition, the dominant belt on north slopes of the Qinling Mountains and Daba Mountains are montane broadleaf-conifer mixed forest or montane deciduous broadleaf forest. The south slope of the Daba Mountains has a unique dominant and characteristic belt of montane evergreen-deciduous broadleaf mixed forest belt, which is different from the north slope of the Qinling-Daba Mountains.

Finally, according to the calculation results based on data from some meteorological sta- 
tions in the piedmonts of the Qinling-Daba Mountains recorded during 1981-2010 (Table 1), the warmth indices of the south piedmont of the Qinling Mountains and the north piedmont of the Daba Mountains are about $120-135^{\circ} \mathrm{C} \cdot$ month, which are consistent with the heat conditions of the warm temperate evergreen-deciduous broadleaf mixed forest zone (Fang and Yoda, 1989). Southward to the south piedmont of the Daba Mountains, the warmth index reaches $140-150{ }^{\circ} \mathrm{C} \cdot$ month, satisfying the heat demand for existence of a subtropical evergreen broadleaf forest belt (Fang and Yoda, 1989). Therefore, according to the heat conditions, the Daba Mountains can be taken as the north-south divide. In contrast, the influence of the Qinling Mountains on the north-south transitional zone is mainly reflected by its influence on rainfall patterns. As shown in Table 1, the annual precipitation sharply decreases from 800-900 $\mathrm{mm}$ to 500-700 $\mathrm{mm}$ in the Qinling Mountains, which influences the dry-wet pattern of the north-south transitional zone. Therefore, the Qinling Mountains are also considered to be an important boundary of the dry and wet climate rather than a temperature boundary (Fang and Yoda 1989; Fang, 1990). Taking the Qinling Mountains as the boundary between the subtropical zone and warm temperate zone in China is only an illusion caused by the lack of moisture (Fang et al., 2002). In addition, according to research on climate changes and vegetation coverage in the Qinling-Daba Mountains, changes of vegetation coverage in the Qinling Mountains are positively correlated with precipitation, but have negative correlation with temperatures (Liu et al., 2016), indicating that precipitation influences the growth of vegetation in the Qinling Mountains more strongly than temperature does. However, the changes in vegetation coverage of the Daba Mountain have certain correlation with temperatures, and have no obvious correlation with precipitation (Ren et al., 2012). This result also indicates that it is more suitable to take the Daba Mountains as the temperature boundary, namely, the boundary between the warm temperate zone and the north subtropical zone, rather than the Qinling Mountains.

Table 1 Climatic variables from weather stations in the piedmont of the Qinling-Daba Mountains (WI: warmth index; AMT: annual biotemperature; MTWM: mean temperature for the warmest month; MTCM: mean temperature for the coldest month; AP: annual precipitation; data from CIMISS http://data.cma.cn/)

\begin{tabular}{|c|c|c|c|c|c|c|c|c|c|}
\hline Site & Location & $\begin{array}{l}\text { latitude } \\
\left({ }^{\circ}\right)\end{array}$ & $\begin{array}{l}\text { Longitude } \\
\quad\left(^{\circ}\right)\end{array}$ & $\begin{array}{l}\text { Altitude } \\
\text { (m) }\end{array}$ & $\begin{array}{c}\text { WI } \\
\left({ }^{\circ} \mathrm{C} \cdot \text { month }\right)\end{array}$ & $\begin{array}{l}\text { AMT } \\
\left({ }^{\circ} \mathrm{C}\right)\end{array}$ & $\begin{array}{c}\text { MTWM } \\
\left({ }^{\circ} \mathrm{C}\right)\end{array}$ & $\begin{array}{c}\text { MTCM } \\
\left({ }^{\circ} \mathrm{C}\right)\end{array}$ & $\mathrm{AP}(\mathrm{mm})$ \\
\hline Songxian & \multirow{3}{*}{$\begin{array}{l}\text { North slope } \\
\text { of Qinling }\end{array}$} & 34.1 & 112.1 & 326 & 128.2 & 15 & 26.6 & 0.8 & 689 \\
\hline Luoning & & 34.4 & 111.1 & 328 & 121.7 & 14.4 & 25.9 & 0.6 & 569 \\
\hline Liquan & & 34 & 108.5 & 543 & 113.3 & 13.4 & 25.7 & 0.9 & 541 \\
\hline \multicolumn{10}{|c|}{ Qinling Mountains } \\
\hline Shannan & \multirow{4}{*}{$\begin{array}{c}\text { South slope } \\
\text { of Qinling } \\
\text { North slope } \\
\text { of Daba }\end{array}$} & 33.5 & 110.9 & 523 & 118.8 & 14.4 & 25.1 & 1.6 & 864 \\
\hline Hanzhong & & 33.1 & 107 & 510 & 123.5 & 15 & 25.6 & 2.8 & 838 \\
\hline Shiquan & & 33 & 108.3 & 485 & 123.4 & 15.1 & 25.5 & 3 & 890 \\
\hline Hanyin & & 32.9 & 108.1 & 413 & 127.2 & 15.4 & 26 & 3.3 & 904 \\
\hline \multicolumn{10}{|c|}{ Daba Mountains } \\
\hline Guanyuan & \multirow{5}{*}{$\begin{array}{c}\text { South slope } \\
\text { of Daba }\end{array}$} & 32.4 & 105.8 & 514 & 140.6 & 16.7 & 26.2 & 5.4 & 929 \\
\hline Wangcang & & 32.2 & 106.3 & 486 & 141.3 & 16.8 & 26.3 & 5.4 & 1158 \\
\hline Nanzhang & & 31.8 & 111.1 & 151 & 135.9 & 16.1 & 27.3 & 2.6 & 912 \\
\hline Wuxi & & 31.4 & 109.6 & 338 & 156.6 & 18.1 & 27.8 & 6.7 & 1091 \\
\hline Xingshan & & 31.4 & 110.7 & 337 & 148.5 & 17.4 & 27.3 & 5.5 & 977 \\
\hline
\end{tabular}


Because zonality is a large-scale issue, previous studies have often used large-scale indices, such as the variation of vegetation and climate in the horizontal zones, to define the north-south divide (Hou, 1981; Zhang and Zhang, 1979). However, as the base belts in the Qinling-Daba Mountains have been used as agricultural zones, wherein most native vegetation fades away, it is difficult to judge the location of the north-south divide. Aside from the influence of large-scale heat conditions, the vegetation distribution in the Qinling Mountains is affected not only by mountain mass blocking cold and warm airflows but also by mass elevation effect. As a result, it is difficult to evaluate zonality based on existing vegetation. For example, the base belt of the south slope of the Qinling Mountains is evergreen shrub, and the appearance of these evergreen shrubs is the result of a combination of zonal temperature and precipitation caused by the effect of the mountain barrier, and it is difficult to confidently identify as a subtropical sign. Mountain altitudinal belts depend on horizontal zones and have characteristics of horizontal zones. Thus, mountain altitudinal belts can be used to identify the features of horizontal belts (Liu, 1981). The research in this paper provides a new method and new argument for determination of the north-south divide of China. The conclusion obtained in this paper, that the Daba Mountains are more suitable than the Qinling Mountains to take as the boundary of the warm temperate zone and north subtropical zone, is consistent with the viewpoints of Song (1999). It is necessary to perform further systematic research based on different scales of the variation in vegetation, climate, soil, and other factors in north-south transitional zone.

In addition, the Qinling-Daba Mountains addressed in previous research mainly referred to the Qinling-Daba Mountains of Shaanxi (Liu, 1995; Liu and Lu, 1990). However, according to the Geomorphological Map of the Qinling-Daba Mountains of China compiled in 1989 by the Department of Geography, Shaanxi Normal University (Geography, 1989), the boundary of the Qinling-Daba Mountains spans six provinces including Gansu, Chongqing, Shaanxi, Sichuan, Henan and Hubei, covering some of the mountains in southern Gansu and the northwestern Sichuan. In previous studies, Xuebaoding was divided into the Hengduan Mountains (Luo, 1983; Yao et al., 2010), and Lianhuashan Nature Reserve in southern Gansu was considered to represent the transitional zone between the Loess Plateau and the Qinghai-Tibet Plateau ( $\mathrm{Li}$ and Zhang, 2000). However, they are divided into the western part of the Qinling-Daba Mountains here, reflecting the role of the Qinling-Daba Mountains as a bridge between the Qinghai-Tibet Plateau and the eastern plain. According to the results of this paper, the Baishuijiang Nature Reserve in the Qinling-Daba Mountains has the most mountain altitudinal belts, with six in total. This area is located in the transitional zone of three physical geographic zones, including the monsoon humid region in east China, the high-cold zone in Qinghai-Tibet Plateau, and the arid region of northwest China. It not only has subtropical characteristic belts represented by subtropical evergreen broadleaf forest and montane evergreen-deciduous broadleaf mixed forest, but also has dark coniferous forest and alpine shrub meadow, which are the components of the eastern edge of the Tibetan Plateau (Sun and Feng, 1998). Viewed in context of the changes occurring throughout natural history, this area has an abundance of species, which laid a good foundation for the formation of mountain altitudinal belts. 


\section{References}

Fang J, 1990. Climate and vegetation in China III: Water balance and distribution of vegetation. Ecological Re$\operatorname{search}(5):$ 9-23.

Fang J Y, Song Y C, Liu H Y et al., 2002. Vegetation-climate relationship and its application in the division of vegetation zone in China. Acta Botanica Sinica, 44(9): 1105-1122.

Fang J Y, Yoda K, 1989. Climate and vegetation in China II. Distribution of main vegetation types and thermal climate. Ecological Research, 4: 71-83.

Feng Z, Zhang C, 1990. Studies on the special characteristics of forest vegetation in Diebu county (1). Journal of Gansu Agricultural University, 25(3): 317-324. (in Chinese)

$\mathrm{Fu} \mathrm{Z,} \mathrm{2004.} \mathrm{Soil} \mathrm{zonal} \mathrm{features} \mathrm{between} \mathrm{Qinling} \mathrm{Mountain} \mathrm{and} \mathrm{Hualong} \mathrm{Mountain.} \mathrm{Journal} \mathrm{of} \mathrm{Baoji} \mathrm{College} \mathrm{of}$ Arts \& Science, 24(1): 68-69. (in Chinese)

Fu Z, Zhang X, Liu S, 1996. The summarize of research on the flora and vegetation of the Qinling Mountain range. Acta Botanica Boreali-Occidentalia Sinica, 16(5): 93-106. (in Chinese)

Gao G, 1986. The natural vertical zone of Shennongjia mountain. Journal of Mountain Research, 4(4): $282-286$. (in Chinese)

Geography D O, 1989. Geomorphological Map of Qinling-Daba Mountains in China. Xi'an: Shaanxi People's Publishing House. (in Chinese)

Guang S, Pei Y, Wang X et al., 1961. Geobotanical zone of Henan province, discussion on the division between north subtropical zone and south warm temperate zone. Journal of Henan Normal University (Natural Science Edition), (2): 1-10. (in Chinese)

Han F, Zhang B, Yao Y et al., 2011. Mass elevation effect and its contribution to the altitude of snowline in the Tibetan Plateau and surrounding areas. Arctic, Antarctic, and Alpine Research, 43(2): 207-212.

Hou H-Y, 1964. Discussion on the principle, basis and the system unit for vegetation regionalization of China. Acta Phytoecologica Sinica, 2(2): 153-179. (in Chinese)

Hou H-Y, 1981. A further discussion on the principle and scheme for vegetation regionalization of China. Acta Phytoecologica et Geobotanica Sinica, 5(4): 285-291. (in Chinese)

Hou H-Y, 1988. Physical Geography of China, Plant Geography (the Vegetation Geography of China). Beijing: Science Press. (in Chinese)

Huang B, 1959. Draft of the complex physical geographical division of China. Chinese Science Bulletin (18): 594-602. (in Chinese)

Huang S, 1988. A description of flora and fauna in Beichuan Xiaozhaigou nature reserve. Resource Development \& Market (2): 7, 19. (in Chinese)

Kang M, Zhu Y, 2007. Discussion and analysis on the geo-ecological boundary in Qinling Range. Acta Ecologica Sinica, 27(7): 2774-2784. (in Chinese)

Lei M, 1999. Vegetation of Shaanxi. Beijing: Science Press. (in Chinese)

Li J, Zhang Y, 2000. A study on the spermatophytic flora from Lianhua Mountain Nature Reserve in Gansu Province. Journal of Lanzhou University (Natural Science Edition), 36(5): 98-107. (in Chinese)

Liu H, 1981. The vertical zonation of mountain vegetation in China. Acta Geographica Sinica, 36(3): $267-279$. (in Chinese)

Liu X, Zhu X, Pan Y et al., 2016. Vegetation dynamics in Qinling-Daba Mountains in relation to climate factors between 2000 and 2014. Journal of Geographical Sciences, 26(1): 45-58.

Liu Y, 1995. Land structure and succession of mountain vertical zones. Journal of Shaanxi Normal University (Natural Science Edition), 23(4): 78-81. (in Chinese)

Liu Y, Lu L, 1990. Exploitation and utilization for agricultural natural resources in Qinling-Daba mountainous region of Shanxi province. Journal of Mountain Research, 8(1): 45-52. (in Chinese)

Luo L, 1983. The summit of the Min Mountain range-Xuebaoding. Journal of the Southwest Teachers College (Natural Science Edition), (4): 134-143. (in Chinese)

Rao C, 1993. Distribution and development of vegetation resources in Wudang Mountain. Journal of Wudang 
(Natural Science Edition), (2): 47-53. (in Chinese)

Ren Y, Zhang Z, Hou Q et al., 2012. Response of vegetation cover changes to climate change in Daba Mountains. Bulletin of Soil and Water Conservation, 32(2): 56-59. (in Chinese)

Shen M, Zhang Y, Chen Y, 2001. Vegetation of the Tianyuhe river valley in Qinling Mountain. Acta Botanica Boreali-Occidentalia Sinica, 21(3): 532-537. (in Chinese)

Shen Z, Hu H, Zhou Y et al., 2004. Altitudinal patterns of plant species diversity on the southern slope of Mt. Shennongjia, Hubei, China. Chinese Biodiversity, 12(1): 99-107. (in Chinese)

Song Y-C, 1999. Perspective of the vegetation zonation of forest region in eastern China. Acta Botanica Sinica, 41(5): 541-552. (in Chinese)

Sun G, Feng H, 1998. The analysis of flora characteristics Baishuijiang Natural Sanctuary in Gansu. Journal of Lanzhou University (Natural Science Edition), 34(2): 92-97. (in Chinese)

Tang Z, Fang J, 2006. Temperature variation along the northern and southern slopes of Mt. Taibai, China. Agricultural and Forest Meteorology, 139(3): 200-207.

Wu Z, Hou H-Y, 1980. Vegetation of China. Beijing: Science Press. (in Chinese)

Xue Z, Wang J, 2010. Vegetation distribution pattern in Micang Nature Reserve located in the west part of Bashan mountains. Shaanxi Forest Science \& Technology (6): 27-31. (in Chinese)

Yao Y, Zhang B, Han F et al., 2010. Diversity and geographical pattern of altitudinal belts in the Hengduan Mountains in China. Journal of Mountain Science, 7(2): 123-132.

Ye Y, Yang Q, Wang M et al., 1999. Studies on forest community diversity in Funiushan Mountain I: Vertical distribution of community and species richness. Henan Science, 17(A06): 61-64. (in Chinese)

Ying T-S, 1979. Observations of the flora and vegetation of Mt. Shennongjia in western Hubei, China. Acta Phytotaxonomica Sinica, 17(3): 41-60. (in Chinese)

Ying T-S, 1994. An analysis of the flora of Qinling Mountain range: Its nature, characteristics, and origins. Acta Phytotaxonomica Sinica, 32(5): 389-410. (in Chinese)

Yue M, Dang G, Gu T, 2000. Vertical zone spectrum of vegetation in Foping National Reserve and the comparison with the adjacent areas. Journal of Wuhan Botanical Research, 18(5): 375-382. (in Chinese)

Zhang B, Wu H, Xiao F et al., 2006. Integration of data on Chinese mountains into a digital altitudinal belt system. Mountain Research and Development, 26 (2): 163-171.

Zhang J, 1981. A research on the line of demarcation between subtropical zone and warm temperate zone in Henan Province from the point view of geo-botany. Acta Geographica Sinica, 36(2): 216-222. (in Chinese)

Zhang X, Zhang Z, 1979. A preliminary discussion on the northern boundary of subtropical zone in China: Based on the distribution of broadleaf woody evergreens on the Qinling Mountain. Acta Geographica Sinica, 34(4): 342-352. (in Chinese)

Zhao F, Zhang B, Pang Y et al., 2014. A study of the contribution of mass elevation effect to the altitudinal distribution of timberline in the Northern Hemisphere. Journal of Geographical Sciences, 24(2): 226-236.

Zhao F, Zhang B, Zhang S et al., 2015. Contribution of mass elevation effect to the altitudinal distribution of global treelines. Journal of Mountain Science, 12(2): 289-297.

Zhu K, 1958. Subtropics of China. Chinese Science Bulletin, 8(17): 524-527. (in Chinese)

Zhu Z, Yue M, 2001. Features of grassland zones in the Qinling Mountains and its northern Loess Plateau. Grassland of China, 23(3): 58-63. (in Chinese) 